\title{
Respiratory Distress in Newborn
}

\author{
MU AHMED
}

Respiratory distress is one of the most common reasons of an infant been admitted to the neonatal intensive care unit ${ }^{1,2} .15 \%$ of term infants and $29 \%$ of late preterm infants admitted to the neonatal intensive care unit develop significant respiratory morbidity; this is even higher for infants born before 34 weeks' gestation $^{3}$. Signs and symptoms of respiratory distress include cyanosis, grunting, nasal flaring, retractions, tachypnea, decreased breath sound with or without rales and/or ronchi, and pallor ${ }^{1}$. A wide variety of pathologic lesions may be responsible for respiratory distress in newborn ${ }^{1}$. Among those, Transient tachypnea of the newborn (TTN), respiratory distress syndrome (RDS), meconium aspiration syndrome (MAS), congenital pneumonia, congenital heart disease (CHD), perinatal asphyxia (PNA), and congenital anomalies as tracheo-oesophageal fistula, and congenital diaphragmatic hernia ${ }^{4}$. In Bangladesh, the second most common cause of neonatal death is birth asphyxia ${ }^{5}$. So we need to focus on rapid recognition and quick management of respiratory difficulties to improve the outcome.

There has been a tremendous advance in the management of respiratory distress such as ventilator therapy with different modes such as Continuous positive Airway pressure (CPAP), conventional mechanical ventilation; ultra high frequency jet ventilation, liquid ventilation, surfactant replacement therapy, sophisticated monitoring and extracorporeal membrane oxygenation all have improved the outcome among the babies with respiratory distress ${ }^{6}$.

The study done by BK Raha et al showed the overall prevalence of respiratory distress was $19.2 \%$ and majority of cases were due to TTN, RDS, septicemia and birth asphyxia. Mortality was minimum (1.8\%) which makes us hopeful. At the same time we should keep in mind that results of their study were comparable with results from developed countries because the facilities available in their NICU were equal to those available in developed countries. In Bangladesh, only $18 \%$ of women make 4 antenatal care (ANC) visits compared to $43 \%$ in urban areas ${ }^{7}$. Coverage of skilled attendance at birth is $36 \%$ in rural areas, compared to $61 \%$ in urban areas. $47 \%$ of newborns in rural areas receive postnatal care (PNC) within 2 days after birth, compared to $69 \%$ in urban $\operatorname{areas}^{7}$. So a major portion of newborns are not able to get those facilities and we have to focus on the preventable causes e.g. birth asphyxia, prematurity, low birth weight, sepsis etc to decrease morbidity and mortality. And we agree with Dr. Bk Raha et al that better obstetrical care and awareness of the risk factors of birth asphyxia among mothers and fetus, along with adequate antenatal and perinatal care for early detection of risk factors and timely intervention may improve the outcome of neonatal respiratory distress, in Bangladesh.

(J Bangladesh Coll Phys Surg 2021; 39: 1-1)

DOI: https://doi.org/10.3329/jbcps.v39i1.50446

\section{Prof. Mesbah Uddin Ahmed}

MBBS, DCH, FRCP (Glasgow), PhD.

Professor of Pediatrics \& Principal

Gonoshasthaya Samaj Vittic Medical College

Dhaka.

\section{References:}

1. Carlo WA, Ambalavanan N. Respiratory Distress Syndrom. ln: Kliegman RM, Stanton BMD, St. Geme J, Schor NF, editors. Nelson Textbook of Pediatrics. 20th edition. Elsevier: 2016.

2. Edwards MO, Kotecha SJ, Kotecha S. Respiratory distress of the term newborn infant. Paediatr Respir Rev. 2013;14(1):29-36

3. Hibbard JU, Wilkins 1, Sun L, et al; Consortium on Safe Labor. Respiratory morbidity in late preterm births. JAMA. 2010;304 (4):419-425

4. Am Fam. Physician American Academy of Family Physicians. 2007;76:987-94.

5. WHO-MCEE estimates for child causes of death, 2000-2015 (http://www.who.int/healthinfo/global burden disease/estimates child cod 2015/

6. Rao GC, Rao MSP. Etiological profile of respiratory distress in first day of life of a newborn baby. Int $\mathrm{J}$ Contemp pediatr. 2017;4(1):210-14

7. Bangladesh Demographic and Health Survey 2014 via the DHS Program STAT compiler. (http://www.statcompiler.com) 